\title{
Deoxycholic acid in gall bladder bile does not account for the shortened nucleation time in patients with cholesterol gall stones
}

\author{
H Noshiro, K Chijiiwa, I Makino, K Nakano, I Hirota
}

\begin{abstract}
The relations between the concentration of deoxycholic acid (DCA), the cholesterol saturation index, and the nucleation time in gall bladder bile were measured to determine the role of DCA in bile in the pathogenesis of cholesterol gall stone disease. Bile was obtained from patients with cholesterol gall stones $(n=30)$, subjects without gall stones $(n=35)$, and patients with pigment gall stones $(n=9)$. Three of 30 cholesterol gall stone patients and 10 of 35 gall stone free subjects were treated with antibiotics by mouth to decrease the concentration of bile DCA and determine the effect of DCA on biliary lithogenecity. Both the percentage and concentration of DCA in bile were similar in patients with and without cholesterol gall stones despite significant differences in their cholesterol saturation indices and nucleation times. Neither the percentage nor the concentration of DCA in bile correlated with either the cholesterol saturation index or the nucleation time. Analysis of subgroups with matching cholesterol saturation indices showed no correlation between the proportion of DCA in the bile and the cholesterol nucleation time. The proportion of DCA in bile was decreased by antibiotic treatment, but this had no effect on the cholesterol saturation index or nucleation time. These results suggest that DCA in bile is not responsible for biliary cholesterol saturation or cholesterol nucleation time. (Gut 1995; 36: 121-125)
\end{abstract}

Keywords: gall stones, gall bladder bile, deoxycholic acid, nucleation time.

Deoxycholic acid (DCA), a metabolite of cholic acid produced by bacterial flora in the intestine, ${ }^{1}$ has been considered a risk factor for cholesterol gall stone disease. An increased proportion of DCA in bile has been shown in patients with cholesterol gall stones compared with subjects without gall stones, ${ }^{2-4}$ and a significant correlation has been shown in patients with gall stones between the percentage of DCA in the bile acid pool and the cholesterol saturation index (CSI) of their bile. ${ }^{56}$ In normal subjects fed physiological amounts of DCA, the molar percentage of cholesterol in bile rose significantly along with the increased proportion of DCA in the bile. ${ }^{7} \mathrm{~A}$ similar result was also seen with cholic acid, the precursor of DCA. ${ }^{8}$ Moreover, when intestinal transit was slowed in healthy volunteers treated with lopamide, their circulating DCA pools expanded and their biliary CSI rose. ${ }^{9}$

A decreased proportion of DCA in bile can be induced by the administration of metronidazole ${ }^{10}$ or ampicillin, ${ }^{8}$ by feeding bran, ${ }^{1112}$ lactulose, ${ }^{13}$ or a preparation of Streptococcus faecium, ${ }^{14}$ or by treating hypothyroidism with thyroxine. ${ }^{15}$ Reduction of biliary CSI was reported to follow these manoeuvres.

Recent evidence has shown that nucleation time, the time to the appearance of cholesterol monohydrate crystal in vitro, seen under a polarising microscope, better predicts lithogenic bile than the CSI, ${ }^{16}$ as supersaturated bile is often seen in healthy subjects without gall stones. ${ }^{17}$ Mucous glycoprotein has been shown to promote the nucleation of cholesterol monohydrate crystals in bile, ${ }^{18}$ and hypersecretion of mucous glycoprotein into gall bladder can be induced through the arachidonic acid pathway or directly by DCA. ${ }^{19-21}$ In artificial bile, nucleation time is shortened when the predominant bile acid is the taurine conjugate of DCA, compared with the taurine conjugate of chenodeoxycholic acid or cholic acid predominates. ${ }^{22}$

Based on this evidence, we hypothesised a close correlation between the concentration of DCA and the nucleation time in gall bladder bile. In this study, we determined the relation between the proportion of DCA and the nucleation time using human gall bladder bile samples. As a reduced biliary CSI was reported in bile samples with lowered DCA, ${ }^{810-15}$ we also examined the effect of decreasing the proportion of DCA by antibiotic treatment on the CSI and nucleation time.

\section{Methods}

\section{PATIENTS}

Gall bladder bile samples were collected from 30 patients with cholesterol gall stones, nine patients with pigment gall stones, and 35 subjects without gall stones. Of these 74 subjects, 10 without gall stones and three patients with cholesterol gall stones were treated with antibiotics, kanamycin at a dose of $3 \mathrm{~g} /$ day and metronidazole $750 \mathrm{mg} / \mathrm{day}$, for three days before intestinal surgery for colonic cancer, a treatment generally used for bowel preparation. ${ }^{23}$ There was no significant difference in age or sex among the five patient groups: 
TABLE I Biliary lipid composition and nucleation time

\begin{tabular}{|c|c|c|c|c|c|c|c|c|}
\hline Group & $\begin{array}{l}\text { No of patients } \\
\text { (male/female) }\end{array}$ & Age (y) & $\begin{array}{l}\% \\
\text { Bile acid }\end{array}$ & $\begin{array}{l}\% \\
\text { Phospholipid }\end{array}$ & $\stackrel{\%}{\text { Cholesterol }}{ }^{\star}$ & $\begin{array}{l}T L C \\
(g / d l)\end{array}$ & $C S I$ & $\begin{array}{l}\text { Nucleation } \\
\text { time (day) }\end{array}$ \\
\hline $\begin{array}{l}\text { UCGS } \\
\text { ACGS } \\
\text { UGSF } \\
\text { AGSF } \\
\text { PGS }\end{array}$ & $\begin{array}{c}27(10 / 17) \\
3(3 / 0) \\
25(15 / 10) \\
10(5 / 5) \\
9(4 / 5)\end{array}$ & $\begin{array}{l}53(12) \\
68(9) \\
61(10) \\
55(18) \\
56(13)\end{array}$ & $\begin{array}{l}71 \cdot 6(3 \cdot 6) \\
71 \cdot 2(6 \cdot 8) \\
72 \cdot 6(5 \cdot 0) \\
70 \cdot 2(5 \cdot 5) \\
74 \cdot 7(4 \cdot 3)\end{array}$ & $\begin{array}{l}20 \cdot 1(3 \cdot 6) \\
18 \cdot 5(5 \cdot 9) \\
20 \cdot 5(3 \cdot 7) \\
22 \cdot 1(4 \cdot 8) \\
19 \cdot 5(3 \cdot 7)\end{array}$ & $\begin{array}{c}8 \cdot 3(1 \cdot 7) \| \\
10 \cdot 3(1 \cdot 1) \\
6 \cdot 9(2 \cdot 1) \ddagger \\
7 \cdot 7(2 \cdot 3) \\
5 \cdot 8(1 \cdot 4) \ddagger\end{array}$ & $\begin{array}{c}10 \cdot 8(4 \cdot 5) \oint \\
9 \cdot 4(6 \cdot 4) \\
14 \cdot 3(4 \cdot 6) \dagger \\
10 \cdot 9(3 \cdot 1) \oint \\
12 \cdot 5(4 \cdot 1)\end{array}$ & $\begin{array}{l}1.25(0.29) \| \\
1.59(0.31) \\
0.96(0.26) \ddagger \\
0.98(0.18) \ddagger \\
0.87(0.18) \ddagger\end{array}$ & $\begin{array}{c}2.9(2.5) \| \\
3.0(2.6) \\
12.0(7.5) \ddagger \\
12.1(6.6) \ddagger \\
15.4(6.2) \ddagger\end{array}$ \\
\hline
\end{tabular}

Values are mean $(\mathrm{SD}) .{ }^{\star}$ : Molar percentage in total lipids. Significantly different from untreated cholesterol gall stone group;

$t: p<0.05$ and $\ddagger: p<0.01$. Significantly different from untreated gall stone free group; $\S: p<0.05$ and $\|: p<0.01$. Abbreviations

used: UCGS, untreated cholesterol gall stone patients; ACGS, antibiotic treated cholesterol gall stone patients; UGSF, untreated gall stone free patients; AGSF, antibiotic treated gall stone free patients; PGS, pigment gall stone patients; TLC, total lipid

concentration; CSI, cholesterol saturation index.

untreated cholesterol gall stone group (UCGS group), antibiotic treated cholesterol gall stone group (ACGS group), untreated gall stone free group (UGSF group), antibiotic treated gall stone free group (AGSF group), and pigment gall stone group (PGS group) (Table I). The patients in the ACGS group had colonic cancer in addition to their cholesterol gall stone disease. Samples from UGSF subjects were obtained during surgery for gastric cancer $(n=20)$, malignant lymphoma of the stomach $(n=1)$, colonic cancer $(n=2)$, liver cyst $(n=1)$, or adenoma of the papilla of Vater $(n=1)$. No patient had biliary tract disorder or gastrointestinal obstruction. None of the patients were obese or suffered from hyperlipidaemia or liver dysfunction. None of the patients had previous bile acid treatment. Informed consent was obtained from all patients.

\section{BILE COLLECTION}

A functional gall bladder was confirmed by preoperative cholangiography or ultrasonography, and bile samples with total lipid concentrations of less than $5 \mathrm{~g} / \mathrm{dl}$ were excluded from the study after biliary lipid analysis. ${ }^{24}$ Bile samples were obtained by needle aspiration, withdrawing gall bladder contents completely to avoid sampling errors caused by stratification. ${ }^{24}$ The fresh, sterile, samples were centrifuged immediately at $100000 \times g$ for 120 minutes at $37^{\circ} \mathrm{C}$ in an ultracentrifuge (Hitachi 55P-62, Tokyo, Japan) and the isotropic, cholesterol crystal free, bile was collected from the interphase and subjected to nucleation time ${ }^{16}$ and biliary lipid analysis as previously described. ${ }^{25}$ Absence of gall stones was verified by preoperative ultrasound and by intraoperative palpation of the gall bladder. Any gall stones present were classified by gross inspection and chemical analysis in the laboratory. ${ }^{26}$ All cholesterol gall stones included more than $70 \%$ cholesterol by dry weight and pigment gall stones contained less than $30 \%$ cholesterol. All fresh bile samples used for the study were negative for bacterial contamination by standard aerobic and anaerobic bacterial culture. Histological examination of all gall bladder specimens obtained from the gall stone patients showed only mild cholecystitis.

\section{NUCLEATION TIME}

Nucleation time was determined in our laboratory as previously reported, ${ }^{27}$ based on the method of Holan et al. ${ }^{16}$ Isotropic, cholesterol crystal free, bile was transferred to small sterile brown glass vials, and was stored in darkness in an incubator at $37^{\circ} \mathrm{C}$ without shaking. Small aliquots were examined daily under a polarising microscope (Nikon, XTP-II), to detect the formation of cholesterol monohydrate crystals, which were identified by their typical rhomboidal structure.

Nucleation time was defined as the number of days until typical rhomboidal monohydrate crystals appeared during a 21 day observation period.

\section{BILIARY LIPID ANALYSIS}

Phospholipids were measured by the method of Bartlett. ${ }^{28}$ Cholesterol and individual bile acids were quantified simultaneously by gasliquid chromatography using nordeoxycholic acid as an internal standard as previously described. ${ }^{29}$ Total bile acid concentration was calculated as the sum of the bile acids. The cholesterol saturation index (CSI) was calculated using a microcomputer program ${ }^{30}$ based on tables provided by Carey.

\section{STATISTICS}

Values are expressed as means (SD). The statistical significance of differences was evaluated using the $\chi^{2}$ test, analysis of variance (ANOVA) or the unpaired Student's $t$ test. Correlation between parameters was tested by linear regression analysis. $p$ Values less than 0.05 were considered significant. ${ }^{31}$

\section{Results}

BILIARY LIPID COMPOSITION AND NUCLEATION TIME

No significant difference was seen in the molar percentages of bile acids or phospholipids in gall bladder bile between the UCGS and the UGSF groups (Tables I and II). The proportion of cholesterol in the bile was significantly higher in the UCGS than in the UGSF group (Table I). The CSI was also significantly higher in the UCGS than the UGSF group $(1.25(0.29) v 0.96(0.26) ; \mathrm{p}<0.01$, Table I). There was no significant difference in CSI between the PGS and UGSF groups $(0.87$ $(0.18) v 0.96(0.26)$, Table I). The nucleation time of the UCGS group was much shorter than those of the UGSF and PGS groups (2.9 $(2 \cdot 6), 12 \cdot 0(7 \cdot 5)$, and $15 \cdot 4(6 \cdot 2)$ days; $\mathrm{p}<0.01$, 
TABLE II Bile acid composition in gall bladder bile

\begin{tabular}{|c|c|c|c|c|c|}
\hline Patient group & $L C A$ & $D C A$ & $C D C A$ & $U D C A$ & $C A$ \\
\hline UCGS $(n=27)$ & $\begin{array}{l}0.6(0.7) \\
\quad(1.0(1 \cdot 2))\end{array}$ & $\begin{array}{l}17 \cdot 2(11 \cdot 7) \\
\quad(23.9(18 \cdot 0))\end{array}$ & $\begin{array}{l}43 \cdot 8(10 \cdot 6) \\
\quad(62 \cdot 3(28 \cdot 7))\end{array}$ & $\begin{array}{l}2 \cdot 3(2 \cdot 0) \\
\quad(3 \cdot 3(3 \cdot 0))\end{array}$ & $\begin{array}{l}36 \cdot 2(7 \cdot 5) \\
\quad(53 \cdot 1(20 \cdot 4))\end{array}$ \\
\hline ACGS $(n=3)$ & $\begin{array}{l}0.0(0.1) \\
(0.1(0.1))\end{array}$ & $\begin{array}{l}6 \cdot 7(8 \cdot 2) \\
(4.9(5 \cdot 7))\end{array}$ & $\begin{array}{l}51 \cdot 5(14 \cdot 5) \\
(78 \cdot 8(75 \cdot 2))\end{array}$ & $\begin{array}{l}0.0(0.0) \\
(0.0(0.0))\end{array}$ & $41 \cdot 7(6 \cdot 5)$ \\
\hline UGSF $(n=25)$ & $\begin{array}{c}0.8(0.8) \\
(1.5(1.4))\end{array}$ & $\begin{array}{c}16 \cdot 1(8 \cdot 6) \\
(31 \cdot 6(23 \cdot 7))\end{array}$ & $\begin{array}{c}44 \cdot 3(7 \cdot 6) \\
(82 \cdot 9(26 \cdot 3))\end{array}$ & $\begin{array}{c}3.5(3.2) \\
(6.9(6.9))\end{array}$ & $\begin{array}{c}34 \cdot 8(10 \cdot 4) \\
(67 \cdot 1(30 \cdot 3))\end{array}$ \\
\hline $\operatorname{AGSF}(n=10)$ & $0.3(0.7)$ & $9 \cdot 7(7 \cdot 0) \dagger$ & $46.8(11 \cdot 2)$ & $2 \cdot 8(2 \cdot 9)$ & $40 \cdot 5(11 \cdot 1)$ \\
\hline PGS (n=9) & $\begin{array}{l}1 \cdot 2(1 \cdot 1) \\
(2 \cdot 0(1 \cdot 8))\end{array}$ & $\begin{array}{c}14 \cdot 1(9 \cdot 5) \\
(25 \cdot 5(22 \cdot 2))\end{array}$ & $\begin{array}{c}48.0(10 \cdot 1) \\
(83.4(36 \cdot 5))\end{array}$ & $\begin{array}{c}2 \cdot 8(3 \cdot 7) \\
(4 \cdot 0(4 \cdot 0))\end{array}$ & $\begin{array}{l}33 \cdot 9(8 \cdot 2) \\
(59 \cdot 4(25 \cdot 4))\end{array}$ \\
\hline
\end{tabular}

Values are expressed as mean (SD) of: upper, the percentage of total bile acid; and, below, the concentrations (mM) of each bile acid in gall bladder bile. Significantly different from UGSF group; ${ }^{\star}: p<0.05$ and $t: p<0.01$. Abbreviations used: LCA, lithocholic acid; DCA, deoxycholic acid; CDCA, chenodeoxycholic acid; UDCA, ursodeoxycholic acid; CA, cholic acid.

Other abbreviations as in Table I.

respectively, Table I). Despite the significant differences seen in CSI and nucleation time between patients with and without cholesterol gall stones, there was no significant difference in the percentage of DCA in the total bile acid or in the absolute concentration of DCA in gall bladder bile among the UCGS, UGSF, and PGS groups (17 (12), 16 (9), and 12 (10) for percentages and $23.9(18.6), 31.6(23.7)$, and $25.5(22.2) \mathrm{mM}$ for concentrations, respectively; Table II).

EFFECT OF ANTIBIOTIC TREATMENT ON THE DCA CONCENTRATION, CSI, AND NUCLEATION TIME IN SUBJECTS WITHOUT GALL STONES In the 10 GSF patients treated with antibiotics, the proportion of DCA was significantly decreased compared with the untreated GSF group (10 (7)\% $v 16(9) \% ; \mathrm{p}<0.05$, Table II). The molar per cent of cholesterol, and the CSI and nucleation time in the bile were not changed, however, by antibiotic treatment. The total biliary lipid concentration was significantly lower in the antibiotic treated GSF group than in the untreated GSF group $(10.9(3.1) v 14.3(4.6) \mathrm{g} / \mathrm{dl} ; \mathrm{p}<0.05$, Table I). In the antibiotic treated CGS group, the proportion of DCA in bile was decreased and the CSI and nucleation time were not changed compared with the untreated CGS group, suggesting a similar response as that of the gall stone free subjects, although the sample number was insufficient for statistical comparison between the groups (Tables I and II).

RELATIONS BETWEEN DCA CONCENTRATION, TOTAL LIPID CONCENTRATION, CSI, AND NUCLEATION TIME

Nucleation time was significantly inversely correlated with the CSI $(r=-0.621, \mathrm{p}<0.01)$, but not with the total lipid concentration $(r=0.077)$. No correlation was seen between the percentage of DCA and the molar percentage of cholesterol, phospholipids or total bile acid in bile $(r=0.042, r=-0.076$, and $r=0.045$, respectively). The percentage of DCA did not affect the CSI $(r=0 \cdot 112$, Figure (A)). Similarly, neither the percentage nor the concentration of DCA in bile correlated with the nucleation time $(r=-0.029$ and $r=0.075$, Figure (B)). The total lipid concentration was not correlated with the percentage of DCA $(r=0 \cdot 005)$.

As no correlation was found between the proportion of DCA and the CSI, the bile samples were divided into four subgroups according to the CSI (CSI $\leqslant 0.75$, $0.75<\mathrm{CSI} \leqslant 1.00, \quad 1.00<\mathrm{CSI} \leqslant 1.25, \quad$ and $1.25<\mathrm{CSI}$ ) to find out if the concentration of DCA was indeed independent of nucleation
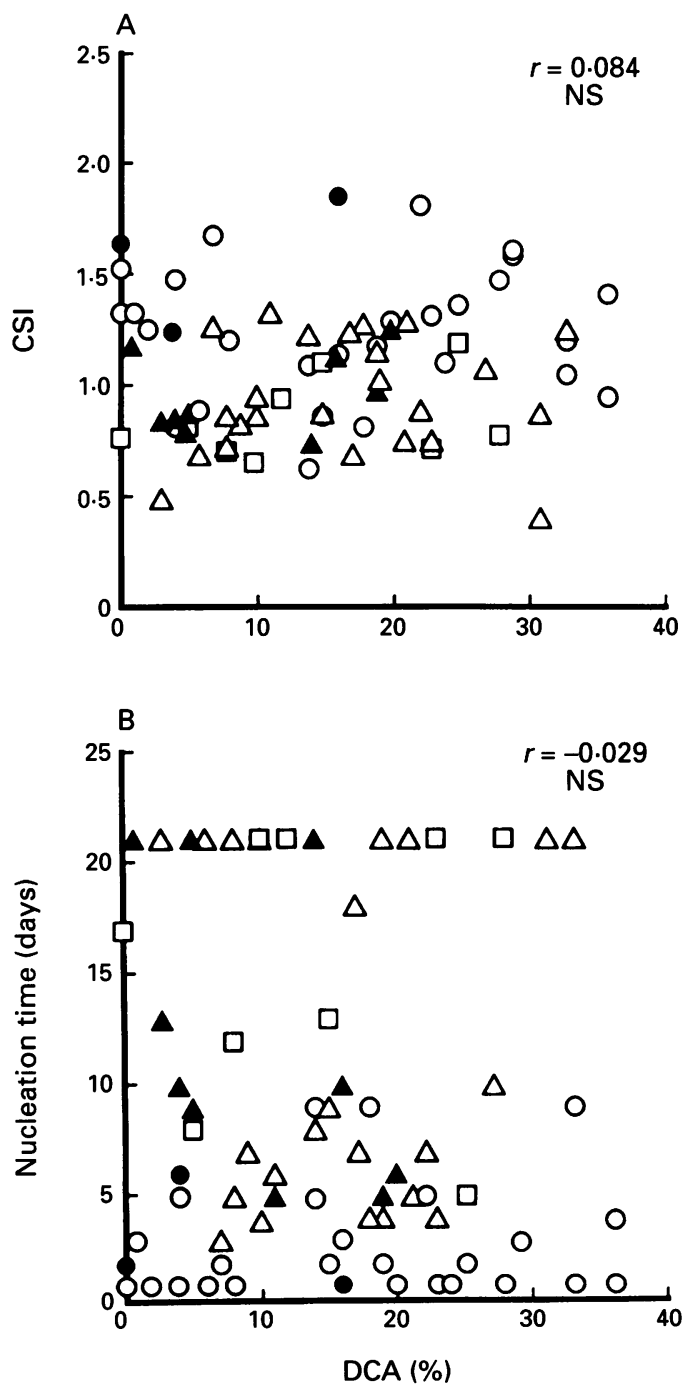

Figure 1: Relations between the proportion of DCA and (A) CSI and (B) nucleation time in gall bladder bile. There were no significant correlations. $\bigcirc$ : untreated cholesterol gall stone patients, 0 : antibiotic treated cholesterol gall stone patients, $\triangle$ : untreated gall stone free patients, $\Delta$ : antibiotic treated gall stone free patients, $\square$ : pigment gall stone patients. NS: not significant. 
TABLE III Effect of DCA on the nucleation time in CSI subgroups

\begin{tabular}{|c|c|c|c|c|c|c|c|}
\hline $\begin{array}{l}\text { Subgroup } \\
\text { (CSI) }\end{array}$ & $\begin{array}{l}\text { Nucleation } \\
\text { time (days) }\end{array}$ & No & $L C A$ & $D C A$ & $C D C A$ & $U D C A$ & $C A$ \\
\hline $\begin{array}{l}\text { I } \\
\text { II } \\
\quad(0.75<\leqslant 0 \cdot 75) \\
\text { III } \quad(1 \cdot 00<\mathrm{CSI} \leqslant 1 \cdot 00) \\
\text { IV } \quad(1 \cdot 25<\mathrm{CSI})\end{array}$ & $\begin{aligned} \mathrm{NT} & \leqslant 5 \\
5 & <\mathrm{NT} \\
\mathrm{NT} & \leqslant 5 \\
5 & <\mathrm{NT} \\
\mathrm{NT} & \leqslant 5 \\
5 & <\mathrm{NT} \\
\mathrm{NT} \leqslant 5 & \leqslant 5 \\
5 & <\mathrm{NT}\end{aligned}$ & $\begin{array}{r}0 \\
9 \\
8 \\
17 \\
8 \\
9 \\
19 \\
3\end{array}$ & $\begin{array}{l}0 \\
0.6(0.6) \\
1.0(0.8) \\
0.8(0.9) \\
0.8(0.3) \\
0.5(1.0) \\
0.5(0.8) \\
0.8(1.1)\end{array}$ & $\begin{array}{l}0 \\
13 \cdot 4(8 \cdot 9) \\
15 \cdot 0(10 \cdot 6) \\
12 \cdot 1(9 \cdot 1) \\
19 \cdot 8(7 \cdot 6) \\
16 \cdot 4(10 \cdot 0) \\
15 \cdot 2(12 \cdot 0) \\
21 \cdot 0(11 \cdot 3)\end{array}$ & $\begin{array}{l}0 \\
46 \cdot 0(12 \cdot 0) \\
43 \cdot 7(5 \cdot 6) \\
45 \cdot 8(10 \cdot 2) \\
43 \cdot 9(9 \cdot 9) \\
43 \cdot 7(8 \cdot 1) \\
45 \cdot 9(11 \cdot 7) \\
47 \cdot 5(8 \cdot 9)\end{array}$ & $\begin{array}{l}0 \\
4 \cdot 1(4 \cdot 4) \\
3 \cdot 0(2 \cdot 9) \\
2 \cdot 5(3 \cdot 4) \\
1 \cdot 8(0 \cdot 7) \\
3 \cdot 3(3 \cdot 2) \\
2 \cdot 5(1 \cdot 8) \\
2 \cdot 0(1 \cdot 2)\end{array}$ & $\begin{array}{l}0 \\
34 \cdot 8(13 \cdot 8) \\
37 \cdot 5(8 \cdot 7) \\
38 \cdot 9(10 \cdot 0) \\
33 \cdot 8(6 \cdot 7) \\
36 \cdot 2(10 \cdot 0) \\
36 \cdot 1(7 \cdot 5) \\
28 \cdot 7(2 \cdot 5)\end{array}$ \\
\hline
\end{tabular}

Values are means (SD) of the percentage of bile acid (\%). Rapid nucleation was defined as NT $\leqslant 5$ days based on data that the

NT in most UCGS patients was within five days (Table I). Abbreviations as in Tables I and II.

time in bile samples with similar CSIs (Table III). The DCA concentration in bile was not increased in bile samples with rapid nucleation time (nucleation time $\leqslant 5$ days) in any CSI subgroup.

\section{Discussion}

It has been suggested that an increased amount of biliary DCA may be a risk factor in cholesterol gall stone disease. Proposed mechanisms for the influence of DCA on the pathogenesis of cholesterol gall stone disease have included raising the cholesterol saturation of bile ${ }^{2-4}$ and causing hypersecretion of mucous glycoprotein. ${ }^{18-21}$ The results in this paper show that neither the proportion nor the absolute concentration of DCA correlated with either the CSI or the nucleation time in human gall bladder bile. An acceleration by DCA of the cholesterol crystal nucleation time without an effect on the CSI was also not seen (Table III). It has been reported that DCA raises the cholesterol saturation of bile by increasing secretion of cholesterol. ${ }^{63233}$ In this study, however, there was no correlation between the percentage or concentration of DCA and those of cholesterol in the bile. Moreover, both the percentage and concentration of DCA were very similar in untreated patients with cholesterol gall stones and in those without gall stones, while the CSI differed significantly between the two groups. These results support previous findings, ${ }^{34-38}$ and confirmed that the raised biliary cholesterol saturation indices in patients with cholesterol gall stones are independent of DCA in bile.

Our finding of no significant difference in biliary DCA between patients with and without gall stones differs from those of some previous studies. ${ }^{2-4}$ There are some possible reasons for the differing results. Firstly, to avoid confounding effects of cholecystitis, only patients with functioning gall bladders, as evidenced by bile with total lipid concentrations greater than $5 \mathrm{~g} / \mathrm{dl},{ }^{24}$ were selected. Some bile samples in previous studies ${ }^{2-4}$ showed extremely low total lipid concentrations. In this study, no significant correlation was seen between the proportion of DCA and total lipid concentration of gall bladder bile $(r=0.005)$. Secondly, control bile samples were obtained from patients with few symptoms whose age and sex were similar to those of the gall stone group. Twenty of 27 untreated gall stone free patients in this study suffered from gastric cancer with few symptoms and normal food intake, while most control patients in previous studies $^{2-4}$ had peptic ulcer or hiatal hernia with abdominal complaints. In contrast, studies using duodenal bile samples obtained from healthy volunteers and gall stone patients showed no significant difference in the proportion of DCA between the groups. ${ }^{34} 353738$ Finally, this is a report of the relation of DCA and the pathogenesis of cholesterol gall stone in Japanese subjects. Racial differences seem to be unimportant, however, because both the CSI and nucleation time of gall bladder bile, which are considered to accurately reflect the tendency to cholesterol crystallisation, were similar in our subjects to those reported for Europeans. ${ }^{16}$

To find out if DCA had an effect on nucleation time independent of the CSI, bile samples were divided into four subgroups according to their cholesterol saturation indices. This was based on previous findings that DCA accelerates hepatic secretion of arachidonic acid into bile. ${ }^{19}$ Arachidonic acid is a precursor of prostaglandins, which in turn mediate mucous glycoprotein secretion from the gall bladder epithelium 2039 and DCA directly stimulates mucous glycoprotein secretion from gall bladder epithelium. ${ }^{21}$ Mucous glycoprotein is a recognised pronucleating factor. ${ }^{18}$ Bile samples belonging to the subgroups with CSI $>0.75$ showed a wide range of nucleation times, suggesting the presence of pronucleating or antinucleating factors in bile. DCA concentration showed no relation, however, to cholesterol crystallisation time in bile samples grouped by CSI (Table III).

Several mechanisms have been reported to reduce DCA in bile. Antibiotic administration is one of these, and metronidazole and ampicillin both reduce the bacterial flora in the colon and interfere with the dehydroxylation of cholic acid, decreasing DCA in bile. Although the proportion of DCA was significantly decreased after treatment with metronidazole and kanamycin in gall stone free patients (Tables I and II), neither a decrease of cholesterol saturation index nor a prolongation of nucleation time in gall bladder bile was seen, supporting previous reports. ${ }^{78}$ These results show that decreasing the concentration of DCA in bile by short term antibiotic treatment had no effect on cholesterol saturation or nucleation time in the bile.

In conclusion, the proportion or concentration of deoxycholic acid in bile did not correlate with either cholesterol saturation or nucleation time of gall bladder bile in patients 
with or without gall stones. A short course of antibiotic treatment decreased the proportion of DCA in the bile without affecting the cholesterol saturation index or nucleation time. These results suggest that DCA does not play an important part in cholesterol crystal nucleation or biliary cholesterol saturation.

1 Morris JS, Low-Beer TS, Heaton KW. Bile salt metabolism and the colon. Scand $f$ Gastroenterol 1973; 8: 425-31.

2 Fissher MM, Youssef IM. Sex differences in the bile acid composition of human bile: studies in patients with and without gallstones. Can Med Assoc f 1973; 109: 190-3.

3 Arnesjo B, Bodvall B, Stahl E. Bile acid patterns of gallbladder and hepatic bile in patients with and without gallstones. Acta Chir Scand 1975; 141: 135-8.

4 McDougall RM, Walker K, Thurston OG. Bile acid alterations in patients with cholesterol gallstones. $\mathcal{f}$ Surg alterations in patients
Res $1976 ; 21: 233-7$.

5 Van den Linden W, Bergman F. An analysis of data on human hepatic bile. Relationship between main bile components, serum cholesterol and serum triglycerides. Scand f Clin Lab Invest 1977; 37: 741-7.

6 Hofmann AF, Grundy SM, Lachin JM, Lan S, Baum RA, Hanson RF, et al. Pretreatment biliary lipid composition in white patients with gallstones in the National Cooperative Gallstone Study. Gastroenterology 1982; 83: 738-52.

7 Low-Beer TS, Pomare EW. Can colonic bacterial metabolites predispose to cholesterol gallstones? $B M \mathcal{F}$ 1975; 1: 438-40

8 Caruli N, Ponz de Leon M, Loria P, Iori R, Rosi A, Romani $M$. Effect of the selective expansion of the cholic and acid pool on bile lipid composition: possible mechanism of bile acid induced biliary cholesterol desaturation Gastroenterology 1981; 81: 539-46.

9 Marcus SN, Heaton KW. Intestinal transit, deoxycholic acid and the cholesterol saturation of bile: three interrelated factors. Gut $1986 ; 27$ : $550-8$.

10 Low-Beer TS, Nutter S. Colonic bacterial activity, biliary cholesterol saturation, and the pathogenesis of gallstones. Lancet 1978; ii: 1063-5.

11 Pamore EW, Heaton KW, Low-Beer TS, Espiner HJ. The effect of wheat bran upon bile salt metabolism and upon the lipid composition of bile in gallstone patients. $A m \boldsymbol{F}$ Dig Dis 1976; 21: 521-6.

12 Marcus SN, Heaton KW. Effects of a new, concentrated wheat fibre preparation on intestinal transit, deoxycholic acid metabolism and the composition of bile. Gut 1986; 27: 893-900.

13 Thornton JR, Heaton KW. Do colonic bacteria contribute to cholesterol gall stone formation? Effects of lactulose on bile. $B M \mathcal{F} 1981$; 282: 1018-20.

14 Salvioli G, Salani R, Bondi K, Fratalocchi A, Sala BM, Gibertini A. Bile acid transformation by the intestinal flora and cholesterol saturation in bile. Effect of flora and cholesterol saturation in bile. Effect of 80-8.

15 Angelin B, Einarsson K, Lejid B. Bile acid metabolism in thyroid subjects: response to substitution therapy. Eur $\mathcal{F}$ Clin Invest 1983; 13: 99-106.

16 Holan KR, Holzbach RT, Hermann RE, Cooperman AM, Claffey WJ. Nucleation time: a key factor in the pathogenesis of cholesterol gallstone disease. Gastroenterology 1979; 77: 611-7.

17 Holzbach RT, Marsh M, Olszwski M, Holan K. Cholesterol solubility in bile. Evidence that supersaturated bile is frequent in healthy men. F Clin Invest 1973; 52: $1467-79$.
18 Gallinger S, Taylor RD, Harvey PRC, Petrunka CN, Strasberg SM. Effect of mucous glycoprotein on nucleation time of human bile. Gastroenterology 1985; 89: 648-58.

19 van Berge Henegouwen GP, van der Werf SDJ, Ruben AT. Fatty acid composition of phospholipids in bile in man promoting effect of deoxycholate on arahidonate. Clin Chim Acta 1987; 165: 27-37.

20 LaMont JT, Turner BS, DiBenedetto D, Handin R, Schafer AI. Arachidonic acid stimulates mucin secretion in prairie Al. Arachidonic acid stimulates mucin secretion in

21 O'Leary DP, Murray FE, Turner BS, LaMont JT. Bile salts stimulate glycoprotein release by guinea pig gallbladder in vitro. Hepatology 1991; 13: 957-61.

22 Hay DW, Cahalane MJ, Timofeveva N, Carey MC. Molecular species of lecithins in human gallbladder bile: hydrophilicity of the bile salt pool determines hydrophilicity of the lecithins. Hepatology 1989; 10: 599

23 Vergnes D, Moatti N, Monrozies X, Lazorthes F. Preoperative colonic preparation using kanamycin and metronidazole: qualitative and quantitative effects on the bacterial flora of the intestine. $f$ Antimicrob Chemother 1980; 6: 709-16.

24 Tera $H$. Stratification of human gallbladder bile in vivo. Acta Chir Scand 1960; 256 (suppl): 8-45.

25 Noshiro $H$, Chijiiwa K, Hirota I. Diurnal variation in cholesterol metastability of hepatic bile and its acute modulation with ursodeoxycholic acid in humans. f Hepatol 1992; 16: 23-30.

26 Yamashita N, Yanagisawa J, Nakayama F. Composition of ntrahepatic calculi: etiological significance. Dig Dis $S c i$ 1988; 33: 449-53.

27 Hirota I, Chijiiwa K, Noshiro H, Nakayama F. Effect of chenodeoxycholate and ursodeoxycholate on nucleation time in human gallbladder bile. Gastroenterology 1992; 102: 1668-74.

28 Bartlett GR. Phosphorus assay in column chromatography. 7 Biol Chem 1959; 234: 466-8.

29 Chijiiwa K, Nakayama F. Simultaneous microanalysis of bile acids and cholesterol in bile by glass capillary column gas chromatography. $f$ Chromatogr 1988; 431 $17-25$.

30 Kuroki S, Cohen BI, Carey MC, Mosbach EH. Rapid computation with the personal computer of the percent cholesterol saturation of bile samples. F Lipid Res 1986; 27: 442-6.

31 Snedecor GW, Cochran WG. Statistical methods. 6th ed. Ames, IA: Iowa State University Press, 1974: 54-81.

32 Hofmann AF. Pathogenesis of cholesterol gallstones. 7 Clin Gastroenterol 1988; 10: S1-11.

33 Caruli N, Loria P, Bertolotti M, Ponz de Leon M, Menozzi $\mathrm{D}$, Medici G, et al. Effects of acute changes in bile acid pool composition on biliary lipid secretion. 7 Clin Invest 1984; 74: 614-24

34 Vlahcevic ZR, Bell CC, Buhac I, Farrar JT, Swell L. Diminished bile acid pool size in patients with gallstones. Gastroenterology 1970; 59: 165-73.

35 Vlahcevic ZR, Bell CC, Gregory DH, Buker G, Juttijudata $P$, Swell L. Relationship of bile acid pool size to the formation of lithogenic bile in female Indians of the South-West. Gastroenterology 1972; 62: 73-83.

36 Carulli N, Ponz de Leon M, Zironi M, Pinetti A, Smerieri $\mathrm{A}$, Iori $\mathrm{R}$, et al. Hepatic cholesterol metabolism in subjects with gallstones: comparative effects of short-term feeding of chenodeoxycholic acid and ursodeoxycholic acid. $\mathfrak{F}$ Lipid Res 1980; 21: 35-43.

37 Ahlberg J, Angelin B, Einarsson K. Hepatic 3-hydroxy-3methyl-glutaryl coenzyme $\mathrm{A}$ reductase and biliary lipid composition in man: relation to cholesterol gallstone disease and effects of cholic acid and chenodeoxycholic acid treatment. $\mathcal{F}$ Lipid Res 1981; 22: 410-22.

38 Ahlberg J, Angelin B, Einarsson K, Hellstrom K, Leijd B. Influence of deoxycholic acid on biliary lipids in man. Clin Sci Mol Med 1977; 53: 249-56.

39 Carey MC, Cahalane MJ. Whither biliary sludge? Gastroenterology 1988; 95: 508-23. 